\title{
Remote Sensing Analysis of Geological Facies and the Open Access Journal: JGRS
}

\section{Xiaoguang Qin*}

Institute of Geology and Geophysics, Chinese Academy of Sciences, China

Geological facies is the combination of geological objectives and their formation environments. Remote sensing is a useful macro-scale analysis tool of geological facies by studying macro-characteristics, interrelations, chronological orders and formation environments of geological objectives.

For the geological facies of tectonic objectives such as faults, folds, depressions and uplifts, the properties and scales of normal, reverse and strike-slip faults can be revealed by studying their linearity, continuity, width and terrain change shown on remotely sensed images. The properties and the evolution process of depressions and uplifts can be analyzed according to drainage network change, underground watercaused color abnormality and other remote sensing features. The chronological order and the movement pattern of tectonic objectives and the evolution of tectonic stress field can be determined by analyzing their interrelation of alternation, superposition, inheritance and cutting.

For the geological facies of igneous objectives such as granites and volcanic rocks, their properties and stages are usually identified and differentiated by analyzing micro-relief-caused image texture and rock property-led color alternation on remotely sensed images. The chronological order of igneous objectives can be analyzed from intruding, covering, breaking and cutting interrelations between them. Combined with microscopic and geochemical evidences and dating of absolute age, the evolution history and the development environment of the igneous objectives can be established and recognized.

For the geological facies of geomorphic objectives such as rivers, lakes (wetlands), terraces, basins and mountains, their properties can be studied by analyzing micro-relief texture and Quaternary sedimentled special color. The environmental evolution history of geomorphic objectives, such as drainage networks, deserts or alluvial fans, etc., can be concluded from the interrelation between these objectives, i.e. changing, overlaying, breaking and cutting, that are represented on remotely sensed images by various objectives remains. Because tectonic are usually important factors impacting the topographic evolution, tectonic features are often considered in studying of geomorphic facies that provide a lot of important evidences for the past globe change's research.

However, the macro-scale remote sensing analysis must be combined with the meso-scale field investigation and geophysical survey, and the micro-scale sediment section study and geochemical analysis in order to understand geological facies' evolution process. This leads to the conclusion that remote sensing geology is not a major research theme in existing scientific journals. Now as a new open access journal of OMICS Publishing Group, the Journal of Geophysics \& Remote Sensing provides an opportunity for all remote sensing geologists to publish their research results in a convenient way.

Open access journal is a new form of magazines that is different from the traditional magazine and allows all worldwide users to freely and unlimitedly copy and use the publication. For most authors, they always wish that more people can read and cite their works. However, they have to transfer the relative right of their articles to the journal when they prepare to publish their articles on a traditional journal. Now, the open access journals give up the rights, meaning that the articles can be freely read by more people. Undoubtedly, it is useful for the spread of knowledge and lossless for authors.

Particularly, the Journal of Geophysics \& Remote Sensing provides several new functions for the convenience of readers. For example, the language translation is a useful tool for non English-native scientists to rapidly understand the ideas of newly published articles on JGRS. Short review period will also attract more scientists to choose JGRS publishing their peer work. We believe that JGRS will be a successful journal with a high impact factor and an important platform where worldwide remote sensing geologists showcase their new achievements.
*Corresponding author: Xiaoguang Qin, Institute of Geology and Geophysics, Chinese Academy of Sciences, No.19 Beituchengxi Road, Chaoyang District, Beijing 100029, China, E-mail: xiaoguangqin@mail.iggcas.ac.cn

Received March 27, 2012; Accepted March 30, 2012; Published April 03, 2012

Citation: Qin X (2012) Remote Sensing Analysis of Geological Facies and the Open Access Journal: JGRS. J Geophys Remote Sensing 1:e103. doi:10.4172/ 2169-0049.1000e103

Copyright: (c) 2012 Qin X. This is an open-access article distributed under the terms of the Creative Commons Attribution License, which permits unrestricted use, distribution, and reproduction in any medium, provided the original author and source are credited. 